apnœea, both of them agree in these three points, that neither had any of the physical signs of phthisis pulmonalis during life; neither was emaciated, but rather both were remarkably plump; and both presented pathological products elsewhere as well as in the lungs. His cases 7 and 8 , of men aged respectively 45 and 24 , are very similar. They are the more interesting that, in addition to the lung-changes found, the cerebral symptoms which were chiefly exhibited during life left some after-death results; while the author himself adds in the title of the last, "Death from a disorder of the brain" (Barrow's translation of Bayle: Liverpool, 1815, p. I73). In Case 7 , "there was nea $i$ an ounce (of serum) at the bottom of the skull, which was as turbid as that contained in the lateral ventricles". (Ib., p. I II.) In Case 8, there was what some pathologists would call now-a-days a "scrofulous" tumour in the medulla oblongata, and a collection on the surface of the brain of miliary round bodies of a dull opaque white, which may have been only Pacchionian bodies. But both cases again agree in these points : the most marked symptoms during life were not on the part of the lungs; the pathological products were presumably those found in general tuberculosis; the writer distinctly tells us there was no emaciation in either.

It would be but time wasted to quote similar cases. My own views as to the pathological products found in all these cases of "acute tuberculosis" are briefly these : There are found frequently together, sometimes alone, numerous vesicular pneumonias, collections of lymphoid cells round the vessels or round the smaller bronchi, orand the distinction from the two last is by no means easy-proliferation of the nuclei in the wall of the capillaries themselves. Each of these products to the naked eye is exactly like the typical tubercle of authors, and, without injection of the tissue and microscopical examination, cannot be distinguished from either of the others, except that, in cases where the vesicular pneumonias are the sole or almost sole production, the lung on section does not present to the hand that feeling of points standing out from the surface; though later, in a shorter or longer period after removal from the body, the lung-tissue collapses and sinks away, leaving the solid nodules more prominent. Such was the case here,* in which even the skill of Mr. Hurst did not catch them in their original superficial flatness.

I have purposely abstained from quoting cases of general tuberculosis in children under my own observation, because I find that they are only examples of what has been stated and illustrated by authors, who have expressed in a far better manner than I can do ideas which carry with them, at least to my mind, the impress of truth. But if, in addition to the evidence not only adduced for the purpose by writers like Buhl, but unconsciously present in the observations of older workers, there were needful, for my own decision, facts within my own knowledge and my own reasoning, they also are forthcoming to uphold the statement of others beside Buhl that acute miliary general tuberculosis is a disease of absorption and infection. And this conclusion, in the very case I am about to state, is the exact contradictory of the older theory - that of Laennec-inasmuch as he considered the larger areas of softening and destruction to be due to the smaller disseminated product, which we hold to be the consequence of some older caseous centre. The one case I wish to mention is this. At the commencement of January I $87 \mathrm{I}$, a boy aged Io was brought to the Children's Infirmary with marked dulness at the left apex ; no increased vocal resonance or tubular breathing; tympanitic resonance over the right chest, which measured a quarter of an inch more round than the left. The pulse was 90 ; the temperature 98.2 . Towards the end of the month, there supervened diarrhœe and night-sweats. Admitted into the hospital, the boy improved in general health, without much change in the physical signs up to the commencement of April. In the second week of July in the same year, he was brought back. The left side was flattened from above downwards. There was absolute dulness over the whole left front; less absolute behind. On coughing, there was tubular breathing, and slight crepitation at the end of expiration. The voice-sound was rather æegophonous and diminished in loudness. The right side was normal. There was no cough; no pyrexia to hand. The bowels were now constipated. Four days later, there was sickness. On the $25^{\text {th }}$ of the month, he was readmitted in the drowsy state of tubercular meningitis. Early on the morning of August 3rd, the fifteenth day after the certain diagnosis of the tubercular meningitis, he died, his temperature the night before having been 102.3; and on the afternoon of that day we made a post mortem examination. The result was as was to be expected : the left lung consolidated; the vesicles filled with cheesy deposit; in the apex, a cavity which communicated with a half-chalky, half-cheesy mass in the position of the

* Drawing of lurg of child: acute tuberculosis : catarrhal pneumonia most thymus, making its way apparently into the pericardium ; perivascular nodules in the pia mater; small miliary tubercles elsewhere ; cheesy bronchial glands. The only comment I can make on this case is this: As a matter of reasoning, it must either be allowed that the antecedent presence of miliary tubercles which, according at least to the language of some, had caused the changes in the lung, gave no fatal indication till they appeared in the adventitia of the pia mater ; or-and I confess the conclusion is easier to my mind-the presence of these perivascular nodules was in all the organs of the body simultaneous, or almost so; later than, and in every probability secondary to, the lung-changes which had already proceeded. There is no need to look upon the cheesy mass in front of the trachea as the original focus; though, as a pathological curiosity, its connection with the lung, and the thinning it was causing in a portion of the pericardium, is extremely interesting. There is one more point connected with this case, to which I may allude later on, which shows the probably hereditary character of what I assume to be the original disease. A younger sister and brother, of whom the latter died, both exhibited symptoms of pulmonary change, commencing, as it did in this boy, at the left apex. I cannot lay my hand on any notes of, nor do I remember making, a post mortem examination of the younger boy. In all probability, it was not allowed.

In everything I have said about this so-called "tubercle" to-day, I have confined myself altogether to that description of it by various writers as applied by them entirely to its supposed presence in the lungs. Unhappily, as I have already hinted, conclusions made as to its occurrence or supposed occurrence there, whether histologically as homologous growths, or pathologically as heterologous products, have been referred to the occurrence of "tubercles", neither histologically nor pathologically similar, in other organs. Backwards and forwards, from its implied type in the lung, its somewhat less defined repetition elsewhere, has this word "tubercle" been tossed, till, if it could speak for itself, it would make of men the same complaint which men, according to Plautus, make of the grds: "Dii nos quasi pilas homines habent." (Capt. I'rol., 22.) If any support for such a proposition be needed, the latest standard works on pathology supply, in their woodcuts, the most various microscopical illustrations, stamped all of them with the very same name- "Tubercle".

\section{THE PREVENTION OF PYÆMIA IN HOSPITAL PRACTICE.*}

By WILLIAM CADGE, F.R.C.S.,

Surgeon to the Norfolk and Norwich Hospital, etc.

In what I am about to say, it is not at all my intention to enter or invite discussion on the nature or treatment of pyæmia, further than to describe what is meant by the term. The subject is too abstruse and complicated for any paper or any oral discussion, and, in proof of this, I would refer to the unsatisfactory and unproductive result of that discussion which took place two years ago at the Clinical Society. The subject of that argument was professedly, Does pyæmia occur in private practice, or is it entirely or chiefly confined to hospitals? No general agreement was arrived at even on a practical point of this kind, and this was chiefly due to a want of agreement as to what should or should not be properly termed pyæmia. Many of the speakers on that occasion confounded together cases of septicrmia; that is, cases where, as in dissection-wounds, or after parturition, a poison is at once absorbed before suppuration is established; cases of abscesses following eruptive fevers, such as scarlet and typhoid fevers; others, again, claimed as pyæmia cases of peritonitis and pelvic cellulitis following lithotomy or herniotomy; and some even spoke of local pyomia.

I would, however, confine the term to the cases having these general symptoms : it attacks mostly, but not entirely, those who have wounds, or have undergone operations; it comes on not immediately, but generally after one or two weeks, with violent rigor, followed by profuse perspiration. To constitute true pyrmia, the rigors and fever-fits must be repeated frequently, once or twice a day, or every few days; the wound in all likelihood alters but little, or looks dry and secretes pus scantily. Rapid exhaustion follows; a sallow skin always, frequently more or iess jaundice; delirium at times; signs of pneumonia or pleurisy. These are the main characteristics of acute typical pyæmia, illustrations of which may be, I grieve to say, abundantly found in the records of this hospital, and it is of this acute typical, or if I may so call it, hospital form of the disease, to which I now refer; and I would ask, in the first place, is this a common disease in the

* Read before the Norwich Medico-Chirurgical Society. 
hospitals of this country? How common or prevalent it really is we cannot exactly tell, for it is only in a few hospitals that accurate records are kept or reports made. But I venture to say, that in almost all hospitals in large towns-hospitals, that is, containing upwards of one hundred beds-pyæmia occurs from time to time, and in many it is always present. In four of the London hospitals, out of 63I deaths after amputation of the thigh, leg, arm, and forearm, no fewer than 86 , or 37.8 per cent., were caused by pyæmia. $\mathrm{Mr}$. Bryant tells us that, at Guy's Hospital, it led to the death of ro per cent. of all the amputations done, and 42 per cent. of the deaths; and Mr. Callender reports that, for ten years, at St. Bartholomew's Hospital, to it was due 39 per cent. of all the deaths following amputations done for disease.

If, then, it was and is the cause of nearly half the mortality of amputations, we may be certain that it prevails to an equal extent after other wounds and operations. Thus, Mr. Erichsen says that, while in University College Hospital, during three years and a half, there were nine deaths from pyæmia after amputations, there were fourteen other deaths from pyæmia, two from septicæmia, and sixteen from erysipelas; and he concludes that this septic miasm or poison commonly exists to a greater or less extent in all hospitals, or in any building, temporary or permanent, where large numbers of wounded and injured persons are congregated under one roof. In the Norfolk and Norwich Hospital, during the last five years, no fewer than thirty-two deaths have taken place from pyæmia.

If this and such as this is the 'experience of British Hospitals, it would be easy, did time permit, to show that even worse results follow in continental hospitals; but I hasten to consider the chief point of inquiry. Is this terrible amount of fatal septic disease the inevitable unavoidable necessity of hospital treatment? the dreadful penalty paid for the skill, the comfort, and the many advantages of such treatment?

Let me glance for a moment before answering this question at the causes leading to acute hospital pyæmia. They are supposed to be well understood, and to be almost comprehended in one word, "overcrowding"; either in the sense of too small a cubic space, or the aggregation of too many open wounds in an otherwise sufficient space, by which the air is rendered impure, a "traumatic atmosphere", as it is called, is produced, and so .pyarmia is surely generated and as surely conveyed from one patient to another. This has been considered by all authorities as the prime factor of pyæmia ; and I have myself publicly stated, and apparently with good reason, that the prevalence of pyæmia in this hospital is mainly due to "overcrowding". Recent experience, however, and a further study of these causes, have led me to think that we have possibly overestimated the effect of thi cause, and underestimated another, to which I will presently allucle.

The answer to the question, Can pycemia be prevented in hospitals? is to be found in the reply to another question, Has it been already successfully prevented in any hospital or by any hospital surgeon?

I affirm, that it has been effectually checked and almost entirely prevented in several hospitals-hospitals, be it understood, where it had previously been frequent and fatal. I will now only allude to two, or at most three; but those will show that the same object has been attained by different, or apparently different, methods.

I. Professor Lister, as we all know, is the champion of the germtheory of disease and of antiseptic surgery. With the truth or error of that theory I have nothing now to do, although I regard it as the most vitally important question of modern surgery; but of the results of the practice of antiseptic treatment of wounds there can be little doubt. He has told us that by it, the wards under his charge at the Glasgow Infirmary, "from being about the most unhealthy in the kingdom, were converted into models of healthiness". For six years, during which he has been surgeon to the Edinburgh Infirmary, although, as I can personally vouch, his wards were dirty and overcrowded by bad cases-warls in which no cleaning had been done for three years, and in which I saw patients lying in "shakedowns" on the floor, and two, three, and sometimes four children in one bedyet, notwithstanding these unfavourable hygienic conditions, he has had only one case of pyacmia in those six years. During the spring and summer of last year, Mr. Lister made a prolonged tour, and visited many continental hospitals, and he has told his experiences fully in his address to the Surgical Section of the British Medical Association at Edinburgh. He quotes the statements of Saxtorph of Copenhagen, of Nussbaum of Munich, of Thiersch of Lcipsig, of Volkmann of Halle, of Bardeleben and Langenbeck of Berlin, and of Von Busch of Bonn, and these statements cannot be more emphatic, that, whereas pyæmia and other septic diseases had been disastrously common in their large hospitals, they had, since the introduction of antiseptic treatment, almost entirely ceased.
2. I have quoted the amputation statistics of St. Bartholomew's Hospital, in which, for ten years, Mr. Callender states that pyæmia caused nearly 40 per cent. of all the deaths. He has very lately published the results of his own experience for the five years during which he has held the office of surgeon, and it appears that the cases of compound fracture, sixty-six in number, all recovered; that of forty-nine amputations, three only died; and that of 405 operations done in the theatre, and therefore operations of some magnitude, there were but three cases of blood-poisoning, and these cases he attributes to faulty management. These splendid results have been obtained by exceeding care on his and his juniors' part in attending to the hygienic surroundings of the patients, to the observance of strict rest, and to absolute cleanliness of wounds; to the use of drainage-tubes, and to carbolic acid dressings.

3. The third instance I will adduce is that of our own hospital. You are probably aware that, for some years past, pyæmia has been a disastrous evil in our wards, to the extent that, in the last five years but one, we have lost thirty-two patients, and only one or two recovered. We believed, as I have before said, that this insalubrity was due chiefly to overcrowding, to the accumulation of too many bad or suppurating wounds in close contiguity. The medical staff endeavoured to remedy the evil by diminishing the number of beds occupied, by limiting the admissions as far as possible, by general care, and by improved ventilation; and, in 1874 , by the performance during six months of many of the severest operations in another building. Notwithstanding all these precautions, the disease remained; and, in the first three or four months of last year, there were four deaths from pyæmia and two or three from traumatic erysipelas.

At that time, in April 1875, we carried out a very complete and thorough change in the nursing department. Previously to that time, the house-surgeon was supposed to have the charge of and direct the work of the nurses, the matron being little more than a housekeeper, and having no knowledge of nursing ; and although, as my colleagues will bear me out in saying, no hospital in the world could have had for the last ten or fifteen years better house-surgeons than we have had, still, I will venture to say, it was simply impossible that they could give that constant and vigilant attention to the personal cleanliness of nurses and patients, and the thousand details and precautions which go to make up efficient nursing. This, surely, is a woman's work; and, although it is common enough now-a-days to see women assuming or claiming the right and power to do men's-especially medical men's-work, I do not believe that men are bold enough to pretend to do as well that which properly belongs to women to do. We appointed a lady to take charge of the nursing department who was a skilled, experienced, and practical nurse. She at once detected the faults and deficiencies in her department, and applied the remedies. To her unceasing watchfulness and care in nursing, aided by the redoubled efforts and personal devotion to the work of the hospital of the house-surgeon, are, I believe, mainly due the results I have now to state.

In the year ending April Ist, I875, there were 294 cases of operations and suppurating wounds treated in the hospital and in the building to which I have referred Among these 294 there were nine deaths from pyæmia, and three or four from traumatic erysipelas. In the year just passed, ending April 1876, exactiy the time during which these changes have been working, there were 350 operations and wounds, and not one death from pyæmia or from traumatic erysipelas. I ought to say that during this year, as in the year before, we have had the use of another house in which most of our important operations and many of the worst accidents have been treated; and to these two changes, but chiefly, I believe, to the great attention to the dressing of wounds, and the details in nursing, may be attributed the cessation of this fell disease. The treatment of wounds has chiefly consisted in the free use of drainage-tubes, the application of carbolised oil on lint covered by cotton-wool, and the occasional use of the full antiseptic method.

For years past, whenever I have visited the hospital after having performed operations, whether severe or trivial, I have always felt an uneasy misgiving lest the house-surgeon should greet me with the remark, "Your patient has had a rigor;" and I dare say my surgical collearues have had the same feeling. Too much have we been accustomed to this remark, and too weil did we know its fatal import. Now, however, and for the past year, we follow up our work with a cheerful confidence that all will be well; we scarcely know what a rigor is-certainly not a true pyamic rigor-and I believe that our death-rate after operations will bear comparison with the healthiest hospital in England. We have purified ourselves, for a year at least, from all septic disease, and I have a sanguine hope and belief that, so long as the present vigilant attention to the nursing and dressing of the 
wounded continues, aided by the reconstruction and enlargement of the hospital now contemplated and so much wanted, so long shall we maintain our freedom from these dire diseases.

I think I have said enough to prove that pyremia is a preventable disease in hospitals. Mr. Erichsen says, in his excellent lectures on Hospitalism, "that when once a hospital has become thoroughly impregnated by these septic influences for a length of time, no hygienic measures can restore it to purity and safety." In this opinion, I hope he has erred, and the evidence I have produced seems to prove it; for in all those numerous English and continental hospitals in which freedom from pyæmia has been secured and maintained, in some instances for years, it had been constantly present for a length of time previously.

By what has been said, the chief means will have been indicated by which prevention is to be obtained.

Mr. Lister obtains it by antiseptic surgery. IIe cares little about overcrowding or ward cleanliness, but he secures most completely surgical cleanliness of wounds. It is true that no amount of overcrowding will produce pyæmia in unwounded patients ; and Mr. Lister, by the carbolic spray and real cleanliness, takes care that no poison or impurity shall reach his patient's wounds.

Mr. Callender, on the other hand, takes care that there shall be no impurity or miasm in his wards; that there shall be no overcrowding, and that the wounds themselves shall be dressed always with scrupulous care.

We, in this hospital, have imitated his care in these respects, but we have, I maintain, discovered this year a source of infection which has, I believe, been too little dwelt upon and too much overlooked hitherto. I mean the infection which creeps along and spreads by impure bed-linen and bed-furniture; by careless neglect in the purification of bandages and linen; and by the disregard of disinfecting and laundry arrangements. As before mentioned, we had taken active steps arainst overcrowding, and in favour of ward ventilation; but it certainly dicl not enter fully into our thoughts that here probably the grentest fault of all was to be found in defective nursing. Very probably in other hospitals these same defects are the unsuspected cause of their unhealthiness; and the remedy will be, not merely to look to the structural aptitude of the building, but rather to the more humble but equally important question 'of nursing and ward-management.

It is probable, as time and experience go on, that the old notion as to the requisite culic space for hospital patients will change. There is no question, that the enormous development of machinery and the growth of population, and, I may add, the advances of operative surgery, have utterly altered the conditions of hospital management ; and I have no doubt that, in these days, operations, and serious wounds and injuries, are vastly more frequent in hospital wards than they formerly were; and, as the proper result of this change, the old idea of 1,500 or 1,600 cubic feet of air as all sufficient will come to be altered to 2,000 or 2,500 .

One other suggestion I would make, as tending to hospital salubrity, viz., the adoption of the plan of isolating, as far as possible, in single rooms, all cases of severe operations or serious accidents, and especially cases calculated to emit noisome odours. We have discovered the value of this plan during the past year, and I sincerely hope that in any extension of our hospital, facilities in favour of this principle will not be forgotten. It was found in the Franco-German war, that in single-roomed huts built in the roughest manner, and in the small huthospitals, there was almost complete absence of pyæmia. Mr. Spencer Wells has said, and with great truth, of ovariotomy, and the same words will of course apply to all operations, "that the surgeon who hopes to obtain better results than have hitherto been obtained, must place his patient, as nearly as possible, in the position of a person in a private house in a healthy situation."

If then, it be proved that pyamia is commonly found in large hos. pitals, so as probably to cause the death of hundreds of patients every year; if it be also proved that by one plan or another it may be wholly or in creat part prevented, then it follows that a great and heavy responsibility rests upon those who have the control and management of such hospitals, and I hope and believe that the time is coming when it will be a disurace, and even an offence, to admit that such a disease exists in warls, which are intended to promote the recovery, and not the death, of the sick poor. It should be compulsory on every hospital to liecp and publish a report of its work, year by year; and if it should thus appear that pyamia and other septic diseases are constantly or frequently occurring within its walls, then I trust that byand-bye some central authority, either of the Local Government Board or of the I'ublic IIealth Department, will have the power and the duty to visit such hospital, and suggest and order the rectification or re- moval of whatever defects, either of construction or internal management, that may be found necessary.

This, however, is a question of the future. In the meantime, it is to be hoped that hospital physicians and surgeons will probe these vital questions to their foundations, and by increased knowledge and experience, will of themselves be enabled to detect the fault, and surely to apply the remedy.

\section{CASE OF TRACHEOTOMY WITH ARTIFICIAL RESPIRATION IN A CASE OF APPARENT DEATH FROM CHOKING.}

\section{By JOHN HARKER, M.D., Surgeon to the Infirmary, Lancaster.}

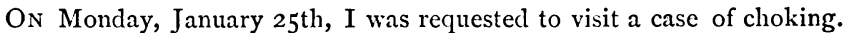
The patient, a man aged 38 , with imperfect sight, could obtain but a precarious living by job-work at public houses. On the day in question, being hungry, he was eating in a ravenous way some cold meat which had been given to him, when he was observed suddenly to choke. Some beer was given to him to drink, when he became worse, livid, and unconscious. At this stage, I was sent for. On examining the patient's glottis with the finger, I found that a piece of meat could be felt, but could not be immediately extracted, as it was large and firmly fixed in the larynx. As respiration had by this time entirely ceased, I proceeded to operate for tracheotomy thus. The patient being seated in a chair, with the head thrown back, I selected a convenient part of the trachea; and, with Trousseau's very serviceable double knife, made a small opening, and introduced a tracheotomy tube. Next, with the aid of a bystander, I used artificial respiration, accomplished by raising the patient's arms well above his head forcibly. This process was known to be effective; as, with each upward movement of the arms, air was distinctly heard to enter the chest with a whistling sound through the tracheotomy-tube. At the end of seven-and-a-half minutes, the patient made a gasp of inspiration, and, after that, became able to breathe. I now tied the tube in position, and took the patient in a cab to the Lancaster Infirmary. When we arrived there, he had so far recovered as to be able, with assistance, to walk up a number of steps to the small ward where I wished to place him in bed. As he continued to recover, he began to make vigorous efforts to bring up the foreign body; a great quantity of mucus frothing came up from the larynx. I now, with a pair of curved throat-forceps-the housesurgeon, Dr. Scott, forcing open the patient's mouth with the handle of a fork-succeeded in extracting a piece of tough meat, which, when spread out, was as broad as two fingers, and about a quarter of an inch in thickness. The cannula was removed from the trachea in the afternoon of the same day. The patient was retained in the Infirmary a week after the occurrence. On Wednesday, he complained of soreness in the lateral regions of the chest; but as his temperature as registered by the thermometer was normal, and there were no abnormal physical signs on auscultation, this $\mathrm{J}$ considered to be owing to fatigue of the respiratory muscles, by reason of the artificial respiration, and no medicine was ordered for him. On the following Monday, he was dismissed, quite well. On recovering, the patient gave this account of the accident. He was in the act of swallowing the piece of meat, when he attempted to speak, and the meat at once entered the windpipe; he was choked, and motioned for a drink; some beer was given to him; he tried to drink, and became unconscious, remembering no more.

\section{A CASE OF SPINA BIFIDA TREATED BY IODO- GLYCERINE INIECTION.}

By MARK LONG, M.D., Hackney.

W. II., $\Lambda$ weLL developed male child, rather above the average size, was born on October 12 th, I 875 . On examination, it was found that both feet were clubbed (talipes w'arus), the knees and hip-joints were rather stiff, and in the sacral region there existed a spina bifida about the size of a small orange. The tumour was semitransparent, not very tense, but became more so when the child cried or was placed in the erect posture ; and the skin covering the upper part was extremely thin, and superficially ulcerated over a considerable space. The tumour was protected from pressure, and the ulcerated part dressed with zinc ointment, under which treatment it slowly healed, and became skinned over in about four weeks. On October 27 th, it became so tense, that I punctured it with a small trocar, drawing off about half an ounce of straw-coloured fluid, and then closed the opening with collodion. The child seemed to suffer no inconvenience whatever from this procedure. On Novem- 